\title{
O ENSINO E A PRÁTICA DA BIBLIOTECONOMIA NA ERA DAS INCERTEZAS
}

\section{César Augusto Castro}

\section{RESUMO}

Análise do ensino e da prática da Biblioteconomia na era das incertezas. Toma-se como referente teórico Baudrillard na suas explicativas sobre a sociedade atual. Discute-se o modo pelo qual os saberes e as práticas dos bibliotecários situam-se nessa sociedade.Questiona-se a chamada sociedade da informação que tem sido tomada pelos bibliotecários brasileiros como uma realidade em que todos indistintamente são participes, quando ao lado desta figura uma sociedade da desinformação.Prepõe-se uma formação para o bibliotecário que transcenda ao discurso unilateral e unívoco

\section{PALAVRAS-CHAVE}

Ensino de biblioteconomia; Sociedade da informação; Sociedade da aprendizagem; Prática bibliotecária.

\section{TEACHING AND THE PRACTICE OF BIBLIOTECONOMY IN THE AGE OF UNCERTAINTIES}

\begin{abstract}
Analysis of the teaching and the practice of biblioteconomy in the age of uncertainties. It is considered as a theoretical reference Baudrillard in his explanations about the present society. It is discussed the way the knowledges and the practices of a librarian are in this society. It is questioned what is called the society of information that has been taken by the Brazilian librarians.Brazilian as a reality of which everybody is, indistinctly, a participant, when besides this figures a society of non-information. It is proposed some kind of education to the librarian that transcends the unilteral and unique discourse, it means, from this society to the learning society.
\end{abstract}

\section{KEYWORDS}

Teaching biblioteconomy; Society of information; Society of learning; Librarian practice. 
As transformações que ocorreram nas últimas décadas do século $\mathrm{XX}$ alteraram significativamente a vida pública e privada de homens e mulheres em todo o planeta. Alterações resultantes de muitos fatores, em especial, o político, o econômico e o tecnológico, que trazem ao mesmo tempo a proposta de integrar a sociedade em rede (CASTELLS, 1999) desorganizam e massificam o social (BAUDRILLARD, 1994).

São estes fatores que tem determinado a conduta da vida individual e coletiva, criando o principio das incertezas, onde para Baudrillard (2002,p.25)

[...] se dar a impossibilidade de avaliar ao mesmo tempo a realidade e a significação do acontecimento na informação, de distinguir as causas e os efeitos em tal processo complexo, o terrorista e o refém ou o vírus e a célula [ ...]. Não se pode mais calcular ao mesmo tempo o preço de uma vida humana e seu valor estatístico. A incerteza se infiltrou em todos os domínios da vida. E isso em função não da complexidade dos parâmetros (essa podemos sempre vencer), mas de uma incerteza definitiva ligada ao caráter irreconciliável dos dados existentes.

Essa incerteza faz que com tenhamos dúvidas quanto ao sentimento de pertença no mundo, dominado por interesses que negam a própria existência dos homens de conviverem e solidarizarem como outros homens e com o mundo (MORIN, 2000)

O sentimento de não pertença pode ser observado no cotidiano através dos meios de comunicação - escritos, orais ou eletrônicos - que circulam nas ruas e praças das cidades ou através do controle remoto que instantaneamente nos coloca a frente de situações negativas de (con)vivência: guerras, assassinatos, explosões de bombas, enfim, quadros de barbáries que nos roubam a liberdade de transitar quando, como, e onde desejarmos. Situações que nos colocam frente ao desconhecido.

\footnotetext{
Não há nada que o homem mais tema do que o contato com o desconhecido. Ele quer ver aquilo que o esta tocando; quer ser capaz de conhecê-lo, ou ao mesmo tempo de classificá-lo. Por toda parte, o homem evita o contato com o que lhe é estranho. À noite ou no escuro, o pavor ante o contato inesperado pode intensificarse até o pânico. Nem mesmo as roupas proporcionam segurança suficiente - quão facilmente se pode rasgá-las, quão fácil e avançar até a carne nua, lisa, indefesa da vítima (CANETTI, 1995, p.13).
}

Estas situações e suas incidências diárias, dadas de modo instantâneo e real, leva-nos a acreditar que somos participes direto desse processo. 
Não é necessário estarmos em Bagdá, Nova Iorque ou na Rocinha para vermos corpos dilacerados e expressões de medo de jovens, homens, mulheres e crianças. A insegurança e a instabilidade do presente e do futuro nessa "[...] sociedade fractal, aleatória, exponencial, a da massa crítica e dos fenômenos extremos [...]” (BAUDRILLARD (2002,p.25), é resultante da ausência de políticas públicas de educação, segurança e de emprego e renda, que atingem a todos os estratos da sociedade brasileira.

No sentido oposto, o mundo tornou-se uma pequena aldeia global, onde independente do espaço geográfico entramos em contato com um número infinito de informações, que nos proporciona uma ilusão ingênua, sobre a possibilidade de absorvê-las em toda sua completude.

[...] nunca é demais lembrar que a sociedade da informação não 'implicar’a, mais cultura. Pois sabe-se bem que informação não e conhecimento e que conhecimento não é cultura. O desafio a enfrentar é este: fazer nascer uma verdadeira cultura daquilo que, para já, não passa de um turbilhão tecnológico e informacional. A cibercultura só merecerá verdadeiramente esse nome quando tiver sabido encarnar as aspirações profundas dos cidadãos planetários que nos estamos a tornar ( QUEAU, 1999,p.406).

Nesse "estado de superpopulação urbana, de superinformação de supercomunicação" Baudrillard (2002, p.18) o ato de aprender constitui-se em uma busca incessante do conhecimento, pelo não saber e principalmente, as incertezas com os saberes historicamente construídos.

Saber este, transmitido na sua perspectiva sistemática através das instituições de ensino. Instituições que passam por un continum processo de mudança do seu papel de transmissora dos conhecimentos acumulados pelos homens e mulheres. Mudanças impostas pelas reformas educacionais que demonstram estreita ligação com os princípios acordados na Conferência Mundial de Educação para Todos, realizada em Jontiem, na Tailândia e na Declaração de Nova Delhi, em dezembro de 1993 e, principalmente, pela imposição de organismos internacionais como o BID e o FMI, que em relação ao ensino superior determinam que: 
[...] o ensino superior se divide em quatro funções: A da formação de profissionais para o mercado de trabalho com um investimento público e privado sob a forma de cursos de graduação; depois cursos de licenciatura curta para os técnicos e para os generalistas [...]. A idéia, portanto, é que há uma elite intelectual que pensa, e depois todo o resto que tem como objetivo o mercado de trabalho. E cada vez o mercado de trabalho saturar, você inventa um curso de formação geral para adicionar valor no currículo de quem compete em um mercado saturado(CHAUI, 2001, p. 22).

Portanto, com objetivos demarcados e estabelecidos pela política neoliberal o ensino, busca formar indivíduos de acordo com tendências pedagógicas, que não são neutras, que se voltam muito mais para atender aos paradigmas dos atuais trabalhos do que formar sujeitos participes de uma nova historia social. Modelos que vêm sendo engendrado nos cursos de biblioteconomia no Brasil.

Cursos que pelo seu caráter formador das mentalidades bibliotecárias absorvem e incorporam perspectivas didático-metodológicas, teórico-práticas e a de natureza tecnológica sem uma análise profunda das implicações políticas ideológicas que subjazem expressões como Sociedade da Informação e seus derivados, clientes de unidades de informação, gestores informacionais, e outras expressões comuns nos discursos dos profissionais e teóricos da área.

O paradigma tecnológico é utilizado por esses atores sociais e pelos gestores e legisladores educacionais como restauradores da educação e das profissões.

Desse modo, é comum encontrarmos em toda a extensão do país programas e projetos educacionais que servem como demonstração estatística do avanço e melhoria da educação e, por conseguinte, restringem-se mais diminuição dos índices do analfabetismo, do que a formação de cidadãos leitores. Indivíduos capazes de ler alem do texto ou de realizar com competência a relação entre o texto e o meio que o circunda, isto é, desenvolver a capacidade de “ [...] situar as informações e os dados em seu contexto para que adquiram sentido. Para ter sentido, a palavra necessita do texto, que é o próprio contexto, e o texto necessita do contexto no qual se enuncia” (MORIN,2000,p.36).

Assim, alunos e professores por força das pressões - legais, técnicas, teóricas, etc absorvem as tecnologias sem o domínio pleno das mesmas, tornando-se simples reprodutores de discursos e softwares que não retratam e nem encontram ressonância nas necessidades institucionais e, principalmente, entre os sujeitos que a utilizam. 
Nesse sentido, afirma Antunes ( 2003, p.91):

\begin{abstract}
Com a conversão do trabalho vivo em trabalho morto, a partir do momento em que, pelo desenvolvimento dos softwares, a máquina informacional passa a desempenhar atividades próprias da inteligência humana, o que se pode presenciar é [...] um processo de objetivação das atividades cerebrais junto a maquinaria, de transferência do saber intelectual e cognitivo da classe trabalhadora [ os bibliotecários, por exemplo] para a maquinaria informatizada. A transferência de capacidades intelectuais para a maquinaria informatizada, que se converte em linguagem da maquina própria da fase informacional, através dos computadores, acentua a transformação do trabalho vivo em trabalho morto.
\end{abstract}

Desse modo, os saberes e os fazeres aprendidos no decorrer da formação acadêmica dos bibliotecários não têm, algumas vezes, um sentido prático para a vida, mas servindo apenas para atender exigências do mundo do trabalho.

Cria-se desta forma na mentalidade dos aprendentes que a leitura, a criatividade, e notadamente, o refletir sobre os saberes teóricos e técnicos próprios do campo da biblioteconomia são atividades secundárias. Sendo substituída a relevância destes aspectos pelo “teclar”, “importar”, “navegar” ou “deletar”, considerando o conhecimento pronto, acabado e definitivo. Cremos que um ensino centrado nessa perspectiva cria autômatos e não sujeitos aprendentes capazes de (re) construir a história.

Na sociedade atual, o ensino e a prática da biblioteconomia têm sido conduzidos, ao nosso ver, pelo imediatismo das relações e pelo atendimento dos condicionantes do mundo do trabalho incerto e mutante. Onde o processo de ensino e aprendizagem pouco estimula a capacidade dos bibliotecários em formação a absorverem as mudanças teóricas, técnicas e tecnológicas de maneira crítica e consciente. Quadro de fácil contorno se fosse restritivo a esta área, no entanto este mesmo processo tem sido repetido nas últimas décadas em todos os seus níveis e campos de saber.

Sendo assim, levantamos duas questões fundamentais, que nos parecer relevantes para a compreensão do ensino e da prática dos bibliotecários na sociedade atual: Como formar um profissional apto para atuar na sociedade presente? Que saberes e que práticas são necessárias para formar um profissional para a sociedade das incertezas? 
É senso comum, afirmarmos que a sociedade presente é dominada e caracterizada pelas tecnologias da comunicação e da informação. Tecnologias que permeiam nossas atividades das mais simples às mais complexas, tanto no campo do privado como no campo profissional. Tecnologias que não devem ser compreendidas como negação de outras que perpassaram pela história da comunicação e da informação. As atuais, em comparação as antecessoras,trazem a vantagem da interatividade e da interconectividade, a ruptura estática da relação entre emissor e receptor e, sobretudo, a cisão com as determinações de tempo e de lugar.

Em torno desse assunto afirma Levy ( 1998,p.21) que "Quando uma pessoa, uma coletividade, um ato, uma informação se virtualizam, eles se tornam ' não-presentes', se desterritorializam. Uma espécie de desengate os separa do espaço físico ou geográfico ordinários e da temporalidade do relógio e do calendário”.

Com esta finalidade, os homens desde a sua origem criaram os primeiros sistemas de escrita, as estradas, as ferrovias, o automóvel e outros meios onde as informações pudessem chegar ao seu destino com rapidez e sem ruídos como afirmam Belo (2002) e Bellei ( 2002).

O processo de comunicação humana encontra na sociedade atual um significado mais amplo, na medida em que, traz a possibilidade de dirimir problemas históricos como as barreiras entre os paises cêntricos e os países periféricos; as possibilidades da pesquisa integrada entre cientistas de instituições e lugares diversos e por trazer outros determinantes no processo de ensino e aprendizagem, a dialética entre professores, alunos e instituições de ensino.

Nesse sentido, Bellei ( 2002,p.129) afirma que:

A tecnologia parece prometer aqui uma liberação geral, e isso não apenas em termos de cidadania e esfera pública, mas, principalmente, em termos de pesquisa no caso dos profissionais da literatura e da cultura, também e principalmente em termos de pesquisa, já que mais pesquisadores, inclusive das áreas periféricas, terão aceso fácil a um volume maior de informação. No ensino, igualmente, o aluno começaria a ter, o acesso a mais informação, mas também, ao trabalhar interativamente com o hipertexto, a ser um produtor de conhecimento e não apenas um consumidor passivo. A tecnologia, que daria poder de voz e voto ao cidadão, também favoreceria o pesquisador e o aluno, porque eles teriam, agora, a sua disposição, bibliotecas virtuais acessíveis no terminal do computador. 
Em oposição as afirmações desse autor, o desejo de um mundo conectado e em rede encontra amplos entraves para os atores envolvidos no processo de ensino e de aprendizagem e, principalmente, para o cidadão comum. Entraves de ordem econômica, social, cultural e educacional.

Portanto, pensarmos na sociedade do conhecimento implica a homogeneidade das formas sociais em todos os setores e um mundo sem fronteiras, em que o avanço nas tecnologias da informação e da comunicação, supostamente, possibilitaria uma barata e intensa transferência de informação e comunicação. Em conseqüência, a difusão das novas tecnologias viria permitir a intensificação das possibilidades de codificação dos conhecimentos, aproximando-os de uma mercadoria passível de ser apropriada, armazenada, memorizada, transacionada e transferida, além de poder ser reutilizada, reproduzida e licenciada ou vendida indefinidamente a custos reduzidos. No entanto, o que ainda se presencia é um modelo elitizado de apropriação da informação e da leitura virtual, que requer computador e linha telefônica para se conectar individualmente, requisito esse fora do alcance econômico de classes sociais menos favorecidas.

Estes são, certamente, os grandes paradoxos profissionais do ensino e da prática dos bibliotecários. De um lado da esfera a atender um grupo que integra a sociedade da informação e do outro eixo, um contingente significativo que se encontra no seu limbo. Diferença que acirra as desigualdades sociais gerando a violência, o desemprego, a economia informal e outras formas de sujeição dos homens e das mulheres.

A bipolaridade entre os incluídos e os excluídos da sociedade atual é explicitada por Castells (2000,p. 124):

Incluídos são os [...] indivíduos ou grupos que possuem as características necessárias para integrarem os mercados globais, por razões laborais, de capital ou de produção de bens culturais, integração na ordem global que lhes permite usufruir de uma cidadania plena, isto é, dos direitos humanos, econômicos, sociais e políticos. Os que não possuem estas características são excluídos, podendo mesmo ser-lhes vedado o acesso a quaisquer direitos.

Daí concordarmos com Hargreaves (2004) quando defende a idéia de que a sociedade do conhecimento é uma sociedade de aprendizagem, na medida em que, o ensino deve desenvolver a capacidade de inovar e de estabelecer compromisso com a inclusão, inclusive a 
digital como pensada pelos idealizadores dos softwares livre. "A luta pela inclusão digital pode ser uma luta pela globalização contra-hegemônica se dela resultar a apropriação pelas comunidades e pelos grupos socialmente excluídos da tecnologia da informação" (SILVEIRA, 2003, p.29).

Desse modo, entendemos que a questão central no ensino da biblioteconomia não e formar um profissional para a Sociedade da Informação, tendo em conta que a mesma, se centra em uma ideologia fundamentalista de mercado onde a criatividade se traduz em ganhos financeiros, estimulando a competitividade e a apreensão de saberes fast-food com objetivo de possibilitar aos aprendentes o ingresso no mundo do mercado de trabalho.

Nessa panacéia pelo imediato, cria-se mentes paranóicas e a educação restringi-se a manualização e a transmissão de conhecimentos padronizados que perdem sentido tão logo sejam substituídos por outra novidade teórica ou prática, que “[...] aumenta o estresse, esvazia a motivação e exaure a disposição”, como afirma Hargreaves (2004, p.98). Assim, a possibilidade de formar homens e mulheres capazes de (re)ligarem os conhecimentos aprendidos nas instituições escolares ficam limitados ao tempo presente (MORIN,1999).

Hargreaves (2004) propõe, uma formação para além da sociedade do conhecimento: "Ela é um cavalo de Tróia: parece trazer presente, mas também traz problemas” (HARGREAVES (2004,p.66).

Uma formação para além da sociedade do conhecimento cultiva a solidariedade, desenvolve o caráter, constrói identidades cosmopolitas e prepara os sujeitos aprendentes para uma prática profissional, criativa e crítico-reflexiva ( SHON, 2000).

Assim, o processo de ensino e aprendizagem se efetiva através de uma dinamicidade onde os sabres e as praticas estão em fluxo contínuo de (re)significação, ou seja, adaptam-se às necessidades presentes e futuras dos aprendentes.

Através do fluxo contínuo, a relação teoria e prática são unidades de uma ação apreendente mais ampla que envolve compromisso sócio-histórico com a profissão e com o meio onde atua o profissional. 
E a atividade teórico-pratica do homem que motiva e promove criticamente, transformações na realidade objetiva e no próprio homem. Nesse sentido, pode-se afirmar que e a atividade ( o conhecimento prático do homem) que assegura ao ser humano condições socioculturais e as bases materiais de sua própria existência. Desse modo, a teoria - conhecimento - e um momento da prática - ação, assim como a prática e um momento da teoria e do próprio pensar ( RAYS, 1997, p. 37).

O ensino centrado nessa base dialética torna-se um trabalho em constante construção, feito e desfeito, que produz e organiza, de modo consciente, os aspectos socioculturais e políticos na formação dos aprendentes. A teoria é um conhecimento que funciona como guia da ação. A prática é a ação, a produção, "É toda a ação do homem transformando o real, transformação essa que pode ser, por exemplo, a negação da própria teoria” (RAYS, 1997, p. 48).

Desse modo, a finalidade da educação escolar do bibliotecário na sociedade atual tecnológica e globalizada - É contribuir para que os alunos desenvolvam habilidades e competências na operalização dos conhecimentos científicos e tecnológicos com sabedoria. Isto significa a capacidade de analisá-los, confrontá-los e contextualizá-los

Capacidade que busca formar um profissional capaz de refletir -na - ação, de modo a ressignificar sua prática cotidiana. “A formação de profissionais reflexivos pressupõe a construção de competências que lhe permitam integrar sua área específica sem perder a visão da totalidade e, sobretudo, refletir sobre o presente e o futuro da prática bibliotecária” (CASTRO, 2002, p.190).

Depreende-se que os saberes e as práticas bibliotecárias não são destituídas dos condicionamentos sócio-históricos e político-educacionais.Desse modo, as práticas bibliotecárias configuram-se como demarcadoras e delimitadoras de suas fronteiras. Práticas que ganham novas configurações na sociedade atual pela incomensurável “[...] quantidade de informação variada sobre o mundo físico, social e cultural com que nossa experiência entra em contato de maneira inevitavelmente parcial e desordenada” (SACRISTAN, 2002, p.210) quer no formato convencional, quer por dos meios eletrônicos, que prescindem de tratamento adequado para que sejam apropriadas para o leitor.

Sendo assim, as tecnologias quando utilizadas pelos bibliotecários, de maneira consciente e crítica, oferecem múltiplas possibilidades de desterritorialização das suas práticas e da instituição biblioteca. 
Práticas e tecnologias que se inovam permanentemente e exigem constantes revisões nos saberes e nos fazeres dos bibliotecários. Daí, a importância de uma educação contínua, isto é, uma educação que ultrapasse a "[...] distinção fundamental entre educação inicial e educação permanente. Aproxima-se de um outro conceito proposto com freqüência: o da sociedade educativa, onde tudo pode ser ocasião para aprender e desenvolver os próprios talentos” (DELORS, 1999, p.117).

A educação contínua baseia-se em quatro pilares:

- Aprender a conhecer-consiste na aquisição de cultura geral que contribua para que o aprendente possa durante toda a vida beneficiar-se das oportunidades educativas. É o princípio do aprender a aprender.

- Aprender a fazer-envolve o desenvolvimento de competências no aprendente para que possa enfrentar situações diversas e a capacidade de trabalhar em equipe.

- Aprender a viver junto - desenvolve a solidariedade e da interdependência humana e no respeito do pluralismo da compreensão mútua e da paz.

- Aprender a ser- desenvolve a personalidade do aprendente e a sua capacidade de agir em situações diversas com autonomia, discernimento e responsabilidade pessoal. Para tanto, não deve negligenciar as potencialidades individuais dos aprendentes como a memória, o sentido estético, as aptidões de comunicação e suas capacidades físicas. (DELORS, 1999,101-102).

Um ensino centrado nestes pilares possibilita aos aprendentes “[...]enfrentar as incertezas, já que vivemos em uma época de mudanças em que os valores são ambivalentes, em que tudo é ligado” (MORIN, 2000,p.34).

Desse modo, o conhecimento apreendido não se torna tudo ou nada, o mundo do trabalho não é o fator determinante dos saberes e dos fazeres biblioteconômicos, mas apenas o termômetro do mesmo. 
Sendo assim, a educação contínua quer:

\begin{abstract}
Civilizar e solidarizar a terra, transformar a espécie humana em verdadeira humanidade torna-se o objetivo fundamental e global de toda a educação que aspira não apenas ao progresso, mas a sobrevida da humanidade. A consciência de nossa humanidade nesta era planetária deveria conduzir-se a solidariedade e a comiseração recíproca, de indivíduo para individuo, de todos para todos. A educação do futuro deverá ensinar a ética da compreensão planetária (MORIN, 2000,p.78).
\end{abstract}

As instituições que tem como atividade a informação, como as bibliotecas, dentre muitas outras tem responsabilidade com a construção da educação do futuro para que todos tenham “[...] o direito de ser iguais quando a diferença nos inferioriza e de ser diferentes quando a igualdade nos descaracteriza” ( SOUZA SANTOS, 2002,p.75).

Em resumo, acreditamos, para concluir que há perdas e ganhos a cada grande mudança. Vantagens e desvantagens. Certezas e incertezas. Mas os períodos de transição tecnológicos são únicos porque revelam para os que nele vivem os elos da História. É um privilégio para educadores e bibliotecários participarem dessa experiência, por mais traumáticas e desafiantes que sejam. A multiplicidade de recursos e oferta democrática de aparatos de ensino deve ser incentivada, principalmente no Brasil, onde infelizmente convivemos com uma grande massa de sujeitos a quem, intencionalmente, foi negado o direito de saber ler e escrever. É necessário, buscarmos aliar práticas educativas que transitem tanto pelo meio impresso como pelo meio eletrônico, na medida em que o múltiplo é includente, enquanto o domínio de uma só tecnologia exclui e marginaliza. Então, que nessa Sociedade do Conhecimento, ao lado dos inputs magnéticos do e-book haja lugar para as velhas práticas e teorias biblioteconômicas. Que os navegadores possam "baixar” o novo livro de Ítalo Calvino na Internet, mas também que os contadores das ricas lendas caboclas da Amazônia continuem a desfilar seus corpos-livro pelas florestas, rios e matas, feito uma biblioteca carregada de livros ambulantes. E que haja sempre obras em papel para nos humanizar entre suas asas.

Por fim, mesmo com todas as adversidades próprias da sociedade da incerteza, ainda é preciso manter a utopia de um mundo melhor. 


\section{REFERÊNCIAS}

ANTUNES, R. Perenidade e (superfluidade do trabalho): alguns equívocos sobre a desconstrução do trabalho. R. Pol. Publ. São Luis, v.7, n.2, p.85-101, jul./ dez. 2003.

BELLEI, S. L. P. O livro, a biblioteca e o computador. Florianópolis: Editora da UFSC, 2002.

BELO, A. Historia \& livro e leitura. Belo Horizonte: Autentica, 2002.

BOUDRILlARD, J. A troca impossível. Rio de Janeiro: Nova Fronteira, 2002.

A sombra das maiorias silenciosas: o fim do social e o surgimento das massas. 4.ed. São Paulo: Brasiliense, 1994.

CANETTI, E. Língua absorvida. São Paulo:Cortez, 2000.

CASTELLS, M. A sociedade em rede. São Paulo: Paz e Terra,1999.

CASTRO, C. A. Formação do profissional da informação: abordagem critico-reflexiva. In:CASTRO, César Augusto (Org.). Ciência da Informação: múltiplos discursos. São Luis: EDUFMA, 2002. p. 186-199.

CHAUI, M. As humanidades contra o humanismo. In: SANTOS, G. A. (Org.). Universidade, formação, cidadania. São Paulo: Cortez, 2001.p.33-50.

DELORS, J. Educação: Um tesouro a descobrir. São Paulo: Cortez, 2000.

HALL, S. A identidade cultural na pós-modernidade. 6.ed. Rio de Janeiro: DP\&A,2001.

HARGREAVES, A. O ensino da sociedade do conhecimento. Porto Alegre:Artmed, 2004.

LEVY, P. O que é o virtual. São Paulo: Editora 34.1998.

MORIN, E. Os setes saberes necessários à educação do futuro. São Paulo: Cortez, 2000. O desafio do século XXI: religar os conhecimento. Lisboa: Instituto Piaget. 1999.

RAYS, O. A. A relação teoria-prática na didática escolar critica. In: VEIGA, I. P. A. (Org.). Didática: o ensino e suas relações. 2 ed. Campinas: Papirus, 1997.

SACRISTAN, J.G. Educar e conviver na cultural global: as exigências da cidadania. Porto Alegre, 2002.

SCHON, D. Educando o profissional reflexivo: um novo design para o ensino e a aprendizagem. Porto Alegre: Artmed, 2000. 
SILVEIRA, S. A. Inclusão digital,software livre e globalização contra- hegemônica, 2003. In: .; CASSINO, J. (Org.). Software livre e inclusão digital. São Paulo: Conrad Editora do Brasil, 2003.

SOUZA SANTOS (Org.). A globalização e as Ciências Sociais. São Paulo: Cortez, 2002. 